\title{
Policy analysis of China inland nuclear power plants' plan changes: from suspension to expansion
}

\author{
Jinxin Zhu' and Gail Krantzberg ${ }^{2^{*}}$
}

\begin{abstract}
s
Background: China's inland nuclear power plants plan has been suspended until 2015 since Fukushima disaster. The policy on inland nuclear power plants becomes uncertain. This paper provides an overview of inland nuclear power plants the safety grantee, economic power on diminishing disparities between Western China and Eastern China, efforts on environmental improvement with reforming of energy restructure and essential public participation. The paper further discusses the government's current policy and successful experience from other countries.
\end{abstract}

Results: The paper gives the recommendations for promoting inland nuclear power plants' expansion, making economy develop healthily, improving environment and introducing public hearing into the nuclear power development.

Conclusions: With proper political guiding, China could obtain significant benefits from expanding nuclear power plants from coast to inland.

Keywords: Inland nuclear power plants; Public policy; West development strategy; Energy restructure

\section{Background}

With China's rapidly developing economy in these years, the problems of power supply restriction, an energy bottleneck, oil and coal supply tension, and so on are emphasized. At the same time, large-scale use of conventional energy sources leads to increased environmental pollution especially in air pollution and GHS emission. In order to raise the proportion of clean energy and catch up with the changing trends, Chinese government makes its mind to accelerate the development of nuclear power as soon as possible.

Ambitious goals for NPPs expansion have been set by China government. By 2020, China must reach a 40GW nuclear power generation capacity, have $18 \mathrm{GW}$ of additional nuclear power capacity under construction, and ensure that nuclear power takes approximately $4 \%$ of electricity generation (i.e., 260-280 billion kWh) (Hou, et al. 2011). However, since Fukushima disaster in Japan,

\footnotetext{
* Correspondence: krantz@mcmaster.ca

${ }^{2}$ Engineering and Public Policy in the School of Engineering Practice, McMaster University, 1280 Main St., W Hamilton, ON L8S 4 L7, Canada Full list of author information is available at the end of the article
}

constructions of new nuclear power plants (NPPs)'s plan have been suspended from March 2011.

According to China's national nuclear plan, China will resume construction of new NPPs projects. Nevertheless, it had lowered its target for the construction of NPPs by 2015, notably by not building additional nuclear reactors at inland locations. Nuclear Power Safety Plan (2011-20) as well as the Mid-term and Long-term Development Plan for Nuclear Power (2011-20) was discussed and passed through executive meeting on Oct $24^{\text {th }}, 2012$. During the 2011-2015 periods, not any nuclear projects will be constructed in inland regions, but only a few projects in coastal areas that have gone through justification processes will be constructed (Xinhua 2012).

While acknowledging that nuclear power expansion plan in China presently is exhibiting symptoms of extreme stress from a combination of sources that include safety concern, economy concern, and environment concern. Moreover, public concern of NPPs' safety is not ignoring due to Fukushima incident. This paper is going to analyze factors related to China inland NPPs' strategies and discuss the current government policies, potential changes 
to current policy from 2012 to 2015, the future of nuclear power after 2015, and the barriers to nuclear power development in China. Some recommendations are also provided.

\section{Inland location NPPs from developed countries and China's high temperature Gas cool reactor technology (safety concern)}

Other countries' primary considerations for NPPs construction are economic and social factors like local demand of electricity, and the situation of the primary energy and power distribution, there is not a distinction in safety between coastal and inland NPPs in the site selection. As a truth, countries like the Canada, France and United States all build a lot of NPPs in inland areas, and the amount of generating reactors and total installed capacity are much higher than coastal NPPs (Dynabond Powertech 2010). General information of percentage of inland reactors is shown in Table 1.

From regulations on NPPs of International Atomic Energy Agency and main nuclear reactors possessing countries, the security objectives and evaluations criteria on coastal nuclear power stations and inland NPPs are identical. There is no difference between regulations of inland NPPs and coastal NPPs' developments. No countries and organizations had ever post special requirements on inland nuclear power plants' safety (National Energy Administration 2012). These countries' operating experience of NPPs demonstrates that safety of inland NPPs can be fully guaranteed.

From Table 1, of the total 442 nuclear stations around the globe, 50 percent are located inland. In Canada, that number is at a striking 86 percent.

After Fukushima disaster, safety of traditional nuclear power plant technology is in fierce debate all over the country, construction work on a power plant using domestically developed, fourth generation technology has already began in Rongcheng City, Shandong Province in

Table 1 General information of world's inland reactors (National Energy Administration 2012)

\begin{tabular}{cccc}
\hline Nations & $\begin{array}{c}\text { Number of } \\
\text { inland reactors }\end{array}$ & $\begin{array}{c}\text { Number of total } \\
\text { reactors }\end{array}$ & $\begin{array}{c}\text { Percentage of } \\
\text { inland reactors }\end{array}$ \\
\hline Global & 220 & 442 & $49.8 \%$ \\
USA & 64 & 104 & $61.5 \%$ \\
France & 40 & 58 & $69.0 \%$ \\
Canada & 12 & 14 & $85.7 \%$ \\
Germany & 14 & 17 & $82.4 \%$ \\
Russia & 18 & 31 & $58.1 \%$ \\
Ukraine & 19 & 19 & $100 \%$ \\
China & 0 & 11 & $0 \%$ \\
Others & 53 & 199 & $26.6 \%$ \\
\hline
\end{tabular}

2012. Because the project gained approved prior to the State Council's decision to impose a moratorium, it were unaffected by suspension of new NPPs project approvals VelkerMatt (2011). Fourth generation reactors represented by high temperate gas-cooled reactors are main trend of NPPs development in China.

China developed the fourth generation technology entirely. In 2003, China's first experimental modulized pebble bed high temperature gas-cooled reactor plant was designed, built by Tsinghua University and began to operate and achieved full capacity operating and supplying power with 10,000-kilowatt to the grid. In terms of its safety, the fourth generation is obviously superior to the former generations' technology, because it uses helium coolant's natural convection to control the reactor even in high temperatures (NGNP Industry Alliance 2012). The pressured water reactors units we see today are massive. However, the actual reactor itself is only about one thousandth the size of the total unit in reality. With the reactor made sufficiently large, it can radiate heat more easily, meaning no power and no water or other cooling fluid is required for high temperate gas-cooled reactor. If normal heat transport systems are not available, heat removal from the reactor occurs naturally and directly to the earth. Even if normal cooling systems are not functional, it takes days to reach limited temperatures (still under temperatures that could melt reactor core) with low energy density of the reactor core and the large heat capacity of the graphite structure. Therefore, reactors can be built and operated independent of water source.

\section{Results and Discussion}

\section{Economy concern}

For planning purposes, China's 31 provinces are divided into three macro-regions-eastern, central and western (see Figure 1). The developments of three regions are ranked with respect to the greatest in the first and the last in the third. Two kinds of disparities between Western China and Eastern China pervade China. The first one is regional disparities that focus on levels of economic development and it varies considerably from Western China to Eastern China. The second is referring to mismatch in energy resources supply and demand. Eastern China suffers severe shortages while Western China is blessed with significant surpluses (HuangTodd and ZhangDaniel 2011).

One important indicator, $\mathrm{Vw}$ coefficient, confirms the existence of regional disparities. The coefficient is used by Williamson (1965). With the regions being represented by China's provinces, it is a measure of variation in weighted GDP per capita the proxy for development-across a country's set of regions. A Vw of zero means the ideal outcome of an absence of any regional departures from a national average GDP; a coefficient of unity represents that the localization of wealth in a single region while all others were destitute. A Vw analysis fortheperiod 1952-2008 


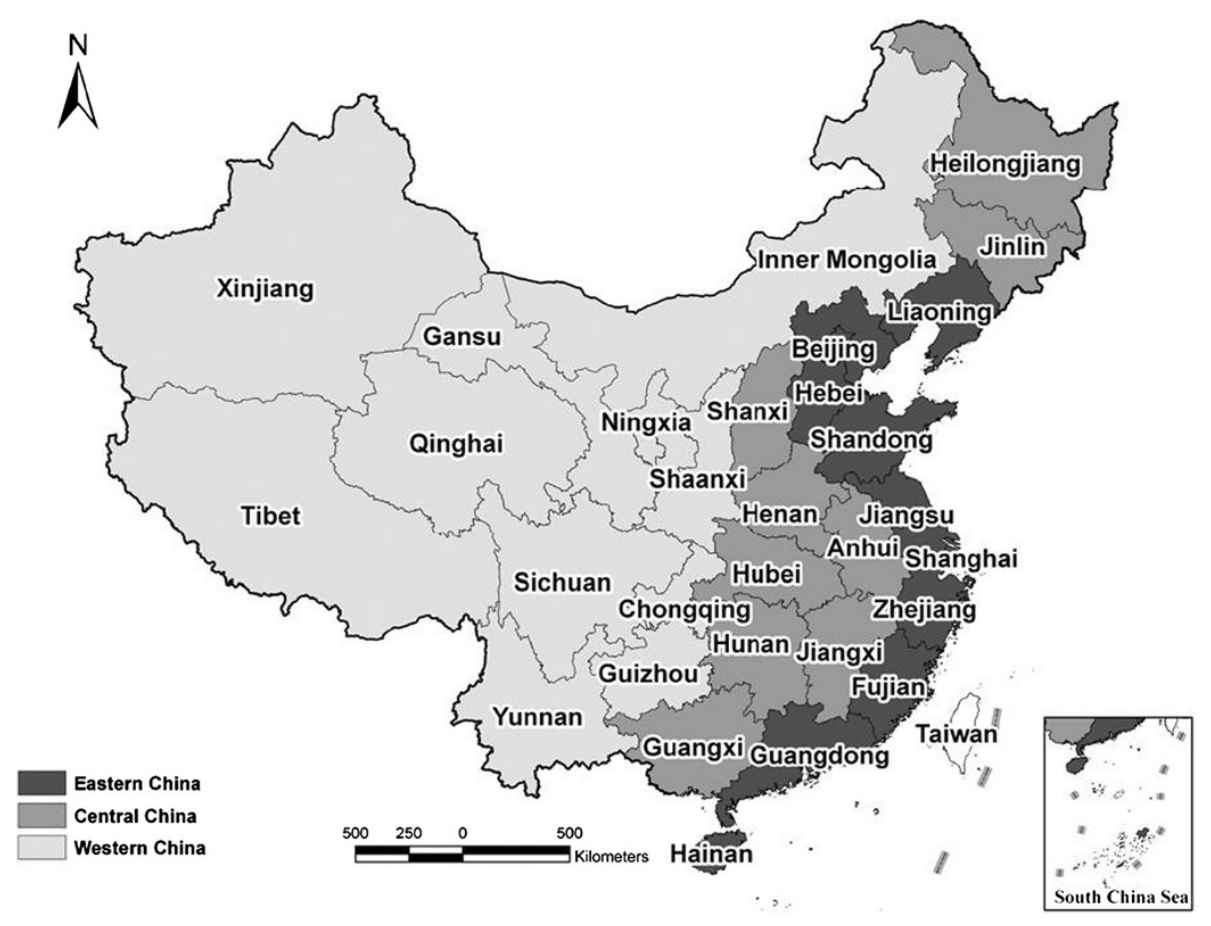

Figure 1 Three macro-regions of China (HuangTodd and ZhangDaniel 2011).

(with per capita GDP standardized on the former year, see Figure 2) demonstrates that Chinese regional disparities have increased shapely and consistently exceeded 0.7 since 1970 (HuangTodd and ZhangDaniel 2011). Little could be detected in the way of gap closing for much of that period, but some trend towards reduction in disparities has become discernible since the West Development Strategy initiated.

This disparities problem not only causes the economic issues to Western China, but also makes the environmental and social issues more severe in that region. Due to the underdeveloped economy, Western China is too dependent on mining energy or non-energy minerals and the over mining makes the fragile ecosystem even worse. Its education and welfare stay in quiet low level for decades because of lack of investment. These issues deter the region's economic development in reverse. In national scale, disparities between Western China and Eastern China in China threat its well-being and integral development. To balance the development of Western China and Eastern China, China government established Western China Development Strategy in 1999 (HuangTodd and ZhangDaniel 2011). This strategy are mainly focusing on pulling demand and market of Western China, reforming the energy structure which is going to be discussed in environmental concern to conserve the ecosystem in this region, keep the society stable, and secure the borderland of China.

Nuclear plant and its construction will boost local economies because of its significant economic benefits. From direct and secondary effects, the average nuclear plant produces approximately $\$ 470$ million economic output in the local community and nearly $\$ 40$ million in

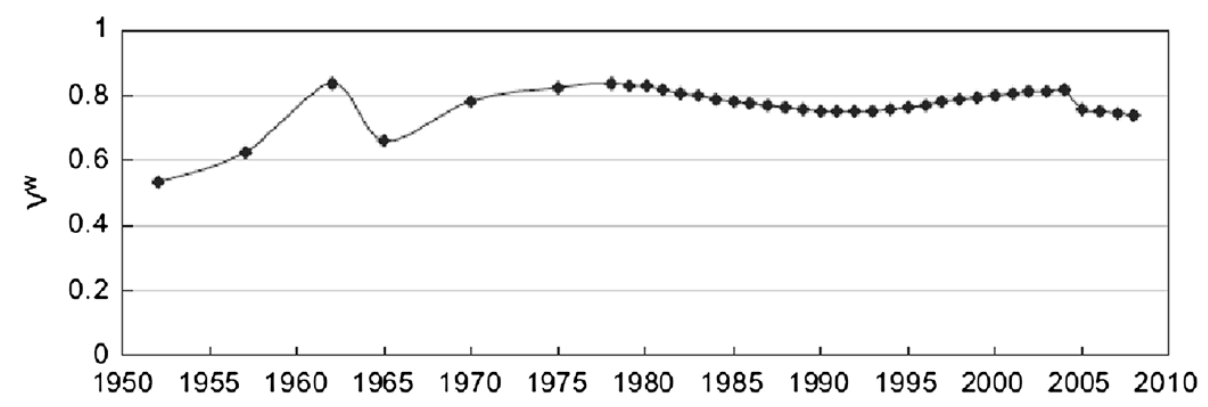

Figure 2 Chinese regional disparities measured by Vw coefficients, 1952-2008 (HuangTodd and ZhangDaniel 2011). 
total labor income for each year (Nuclear Energy Institute of United States 2012). The direct effects reflect the labor, goods and services of plant's expenditures. The secondary effects include subsequent plant expenditures related to the presence of the plant and its employees that penetrate into the local economy. Analysis illustrates that $\$ 0.04$ net benefits in the local community come from every dollar spent by the normal NPPs' construction. The NPPs generates nearly \$16 million in local tax revenue for each year (Nuclear Energy Institute of United States 2012). The tax revenue could benefit education, transportation, and other local infrastructure. Nuclear power plants provide substantial economic benefits during their decades of operation. The taxes, direct and secondary expenditure from NPPs strengthen the economies of local communities and hosting a new nuclear plant will give a similar boost to any community. With different plant size, a new nuclear plant represents an investment ranging from $\$ 6$ billion to $\$ 8$ billion including interest (Nuclear Energy Institute of United States 2012). Moreover, construction of a new nuclear power plant will provide a substantial boost to manufacturers and suppliers of commodities such as steel, concrete and cement.

Current Chinese nuclear expansion plan that only covers the coastal regions is going to aggravate the disparities between these two regions. For NPPs' strong power on boosting economy, they can be a powerful tool to cooperate with Western China Development Strategy to realize its main purposes.

\section{Restructure of energy (Environment Concern)}

In China, coal covering $60 \%$ of the primary energy and $75 \%$ of the power generation leads to irrational energy structure. The coal based energy structure causes serious problems of environmental pollution and emission of greenhouse gases (GHG). China has become one of the most polluted countries in the world. For example, China emitted $20 \mathrm{Mt}$ of SO 2 and $3 \mathrm{Gt}$ of $\mathrm{CO} 2$, both ranked the world No. 2 in 2006. Environmental pollutions cause the economic loss accounting for 3-7\% of GDP in China. If these problems could not be solved properly and quickly, they will hinder the further development of the country. The China Energy Policy (2012) published by the State Council said that China decided to make up to 45 percent reduction of its carbon dioxide emissions by 2020 (Tiantian 2012). To achieve that goal, China has to shut down numerous coal plants and replace them with clean energy plants.

Simultaneously, compared the consumption of energy with east which is always in energy crisis, west only took less than $30 \%$ of total. As shown in Figure 3.

The West-East Power Transmission Project aims to turn the rich energy resources in West China into electricity and to transmit the electricity to East China, the economically dynamic and energy-deprived region of the country (Ouyang, and Changyu 2002). It is an important part of the West Development Strategy of the Chinese government, which will enhance the optimization of energy resources contributing to the healthy development of the national economy. This project will not only solve the energy crisis and the severe environmental contamination of Eastern China but will also transform the abundant resource of Western China into an economic advantage that will help mitigate poverty there. In this way, the WestEast Power Transmission Project will promote the sustainable development of the whole country.

There are three main national power flows from Western China to the southeast coastal areas, in particular, the Guangdong province and Shanghai city referring to the West-East Power Transmission Project (Kang et al. 2012). As shown in Figure 4.

As a result of the rapid expansion of the West-East Power Transmission Project, air pollution is serious in the northern passageway region mainly where consists of coal-fired power plants, especially for Eastern China, and the main air pollutants are PM and SO2 (Zhigang et al. 2005). Thus, the government and public have shown great concern about the proposed power plants in this region's impacts on environment. It is very important, therefore, to understand the impacts of building new clean power plants on improving the air quality in this region.

Nevertheless, Western China's energy shortfalls have surfaced with respect to remaining reserves. China's total remaining oil reserves 1.48 billion barrels by the end of 2009. The reserves/production (R/P) ratio of it was 10.7 years, which was far below the world's average oil $\mathrm{R} / \mathrm{P}$ ratio of 45.7 years. In terms of remaining natural gas, it reserves totalled 2.46 trillion cubic meters with an $\mathrm{R} / \mathrm{P}$ ratio of 28.8 years, which is lower than the world's average natural gas $\mathrm{R} / \mathrm{P}$ ratio of 62.8 years. Remaining coal reserves 1.145 billion ton in total with an $\mathrm{R} / \mathrm{P}$ ratio of 38 years which is far below the world's average of 119 years (British Petroleum (BP). 2011). Western China's energy shortfalls will not only affect local development, but also will threat the whole country's economy growing and environment improving. Needs for clean energy plants planned in these regions are urgent now.

\section{Public concern}

In addition to technical and economic factors, the public understanding and acceptance to the nuclear power play an important role in the development of nuclear power. The familiarity of public towards nuclear power that is terminology of public understanding is an important impact factor on public acceptance. With the increased familiarity with nuclear power, the proportion of people who consider NPPs' safety was corresponding increased. The percentages of public, scientists, energy scientists 

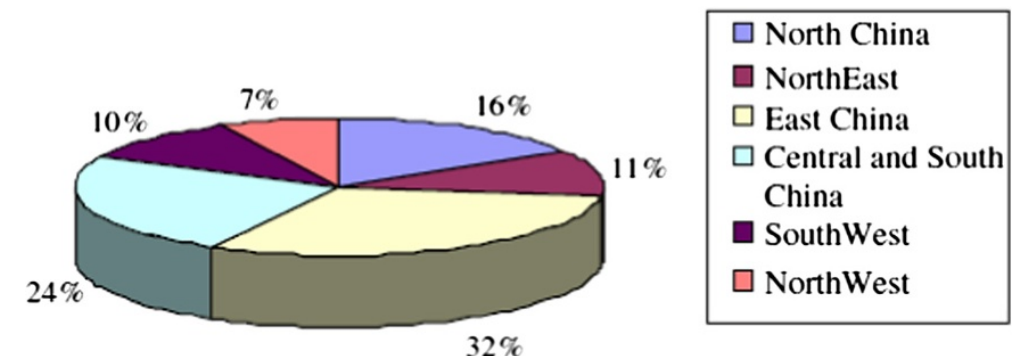

$32 \%$

Figure 3 Electricity consumption by region (2000) (China Statistics Press 2002).

and nuclear experts who believed the NPPs' safety were respectively 40\%, 60\%, 76\% and 99\% (Barke RP HC JenkinsSmith 1993). A study on the level of knowledge and attitude of nuclear power among Chinese residents around the Tianwan nuclear power plant within a radius of $30 \mathrm{~km}$ in Jiangsu of China shows the level of understanding and acceptance of nuclear power was generally not high (Ningle et al. 2012). Other 10 operating NPPs in China have the same situation.

Low level of understanding and acceptance of nuclear power from public will cause serious civic activism like local protest groups. Main issue prompting some local groups and communities to oppose nuclear projects is sensitivities over nuclear fuel leak risks. Local protest groups and adverse public opinion are emerged to challenge the legitimacy of proposed projects by a strong NIMBY (notin-my-back-yard) element, especially in rural areas (International Atomic Energy Agency 2002). Although Chinese history is rife with prominent examples of civic activism, opposition groups have been unable to stop nuclear power development. When a small group from local communities tried to protest licensing of the Daya Bay plant, officials' detained and arrested them. When more than one million people in Beijing signed a petition against nuclear power, Chiang Hsin-Hsiung, the Minister of Nuclear Industry, rebuffed the complainants by issuing a statement that the government "the unscientific objections from some people would not halt the Daya Bay project". When United Kingdom authorities and the Hong Kong Civic Association came out a series of reports questioning the safety of Daya Bay, the government answered "reports compiled by other countries do not constitute legal documents" and thus held no sway over the licensing process (Zhou SXZhang 2010). With no nuclear power mishaps happening, civic activism against nuclear power has waned since the late 1980s. However, the recent events at the Fukushima Daiichi nuclear power plant in Japan have resulted in a great focus on understanding both the safety of nuclear power and the public understanding and acceptance of nuclear power (FoE, F.o.t.E.,

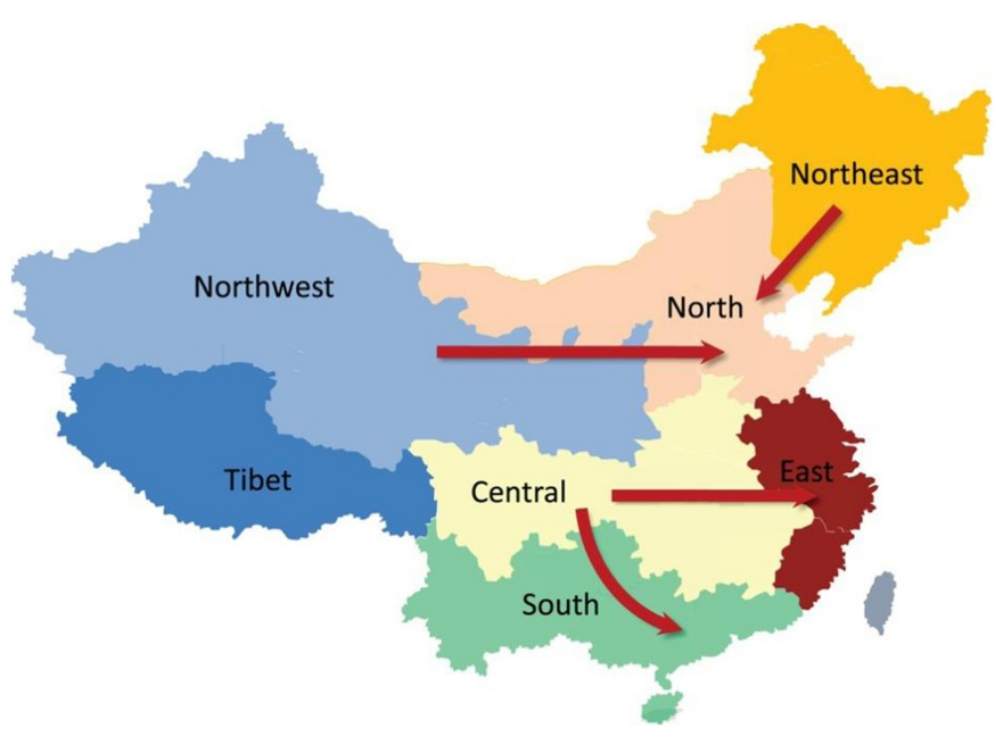

Figure 4 China's national power flow pattern (Ouyang and Changyu 2002). 
GfKNOP 2011). Coercion policies of Chinese government like these, nowadays, lose their power on controlling of society and result in serious potential problem for social security.

On August and October 2012, plans to expand petrochemical plants in northern and eastern China have been shelved after days of protest (BBC NEWS 2012). The plants are producers of PX (a carcinogenic petrochemical used to create raw materials for the production of polyester film and fabric). Tens of thousands protested against chemical plants in Dalian city and Ningbo city. Environmental protests have been more common and influential in China. Many Chinese are becoming more environmentally aware and are deeply concerned about pollution and living quality surrounding them. China policy makers started to pay attention to public voice on NPPs. There are some changes made in its official documents. On March 2012, the National Nuclear Safety Administration
(NNSA) announced "if the environmental impact report does not have a public participation chapter, NNSA would not accept the report. According to the announcement of China's State Environmental Protection Department (SEPA), public participation will run through the whole process, and projects which have strong objections are likely to be stopped." (Dynabond Powertech 2010).

To deal with public issues, experience from other countries is quiet valuable for China. The UK Government's latest National Policy Statements for Energy Infrastructure recognised "there may be positive and negative effects from the construction of new nuclear plants and that organisations applying for site license should identify these effects in their license application." (DECC 2010). Although there are no specific comments on mitigating or avoiding these effects, the activity involved public participation is still widely adopted in nuclear power area in UK. The UK Health and Safety Executive has invited public

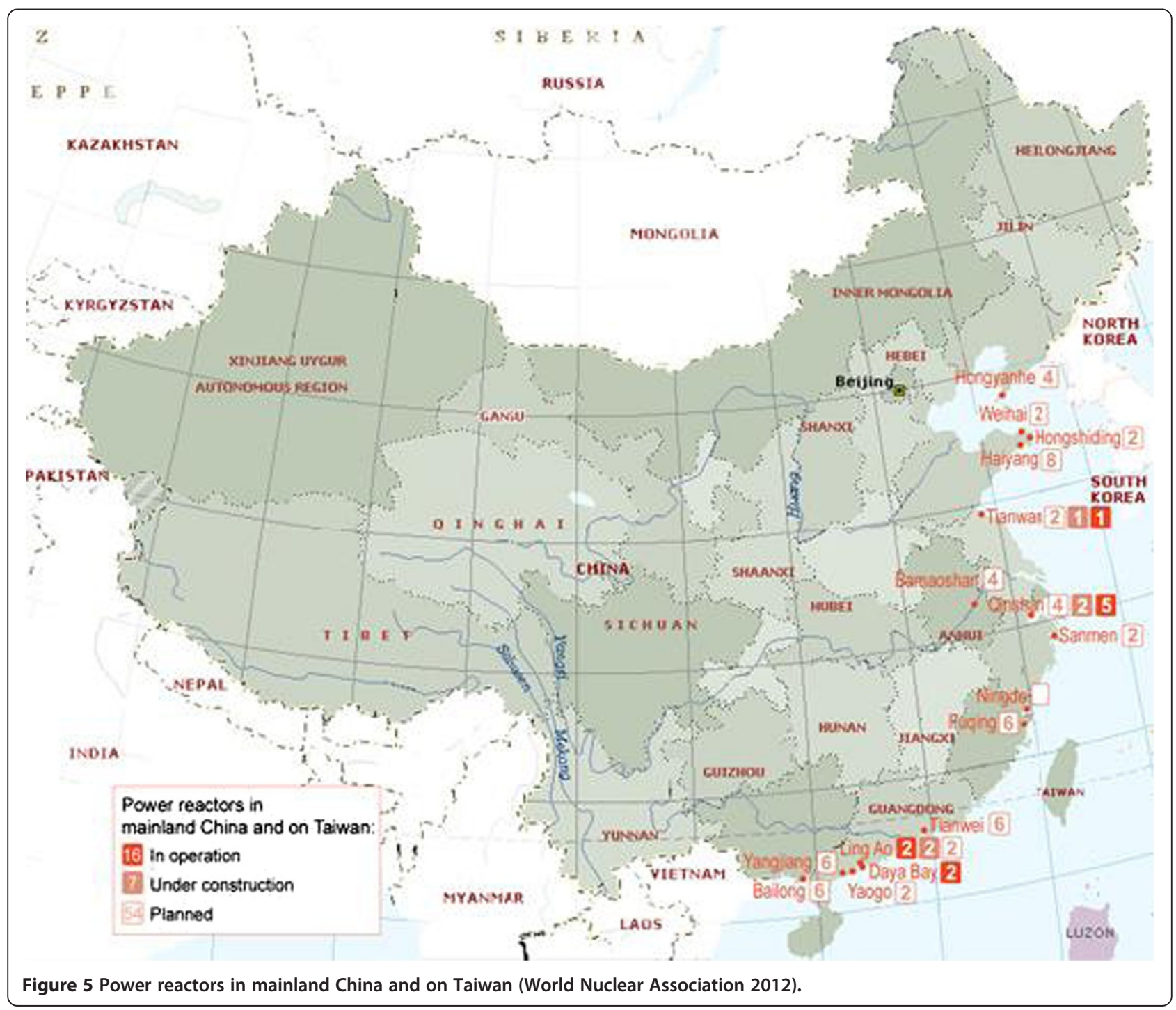


input into its Generic Design Approval (GDA) process for the assessment of new nuclear reactor designs (HSE 2009). However, as the designing or licensing is almost finalised, any changes are might very costly and time consuming, and it is rare that such changes that are not critical for the safety will be made, even if they have potential ability to enhance the socio-economic benefit of the plant. Therefore, making changes earlier in the designing and licensing process would be less costly and more efficient.

\section{Methods}

After Fukushima disaster in Japan, China NPPs' expansion map changed as shown in Figure 5. Only coastal NPPs passed the new nuclear power plant project approvals. This is because dumping radioactive contaminations into sea has much lower risk and cost than dumping into river once the leaking happened in NPPs. However, only selecting locations for NPPs in coastal areas will not be able to meet the future needs of China's sustainable development. To maintain the energy supply for inland provinces which are suffering energy shortfalls and environmental contamination, NPPs are urgently need to be constructed and planned in these regions (Dynabond Powertech 2010). Aforementioned safety concern is the premise for satisfying this urgent need. The successful development of inland NPPs in several leading country such as USA, France and Canada shows that safety is not a main barrier for China to overcome to cover its inland province with nuclear power. Besides, the maturity of China self-developed high temperature gas cool reactor technology will make the siting process of NPPs independent from the limitation of closing to shore of river, lake or coast. Government has large flexibility to cover the benefits of NPPs expansion plan with inland provinces.
But the Fukushima disaster does reveal some designing flaws in NPPs like insufficient emergency producers design. So, revaluation and reexamination is necessary to the initial design of inland NPPs during the 3 years suspension from 2012 to 2015. However, if inland NPPs construction is put off easily by a slight risk, it would be a huge loss of great opportunities to achieve sustainable economy for China.

Disparity between west and east in China hinder the economy from developing healthily. Primary barrier is energy and resource misplacing as mentioned in previous section. West has main fossil fuel resources storage in China.

Misplacing and energy shortfalls make Western China's economy much more depressed and make disparity from Eastern China more severe. Following Western China Development Strategy, NPPs should be planned at inland locations. Not only boost local economy at west, but also improve the mobility of factors of production between west and east. The economic and trading cooperation and the mobilization of capital between Western China and eastern regions are the productivity of capital and could complement technological advances in Western China of the country. With these benefits, construction and planning of inland NPPs will contribute to diminish disparities and eliminate the risk of the economic gap between Western China and Eastern China being lager. Therefore, improve the society stability in Western China and remit the contradictions in whole country.

Western China-East Power Transmission Project has been proved to make a great contribution to environment improvement of China by reducing the transmission and burning of fossil fuel. However, coal fired plants from northern passageway of the project's environmental problems are still serious and these problem have the trend to

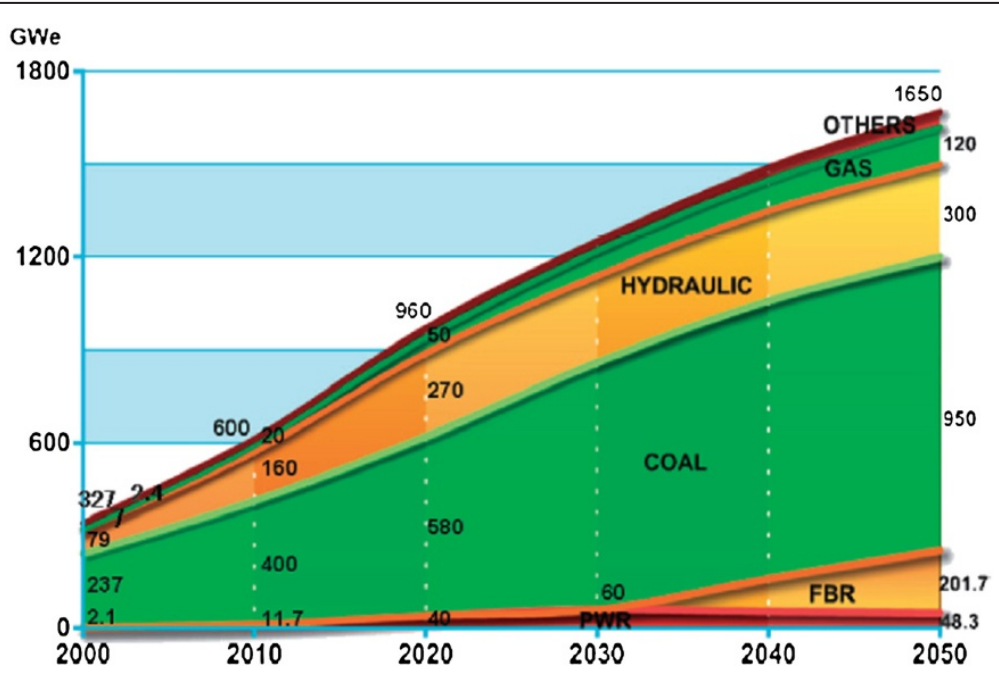

Figure 6 The electricity capacity development envisaged in China by 2050. 
be worse due to the big energy gap for both west and east. To mediate the energy supplying intensity and improve the air-quality in western regions, connecting clean energy generators to electricity grids of northern passageway would be dispensable. In perspective of Chinese electricity capacity development, percentage of coal-fire electricity will decrease with respecting the growing percentage of nuclear power (see Figure 6). In terms of nuclear power's consistency supplying and low cost to generate characteristics, it is most stable and affordable power resource for west compared with solar and wind power. Policy makers should consider increasing the nuclear power's percentage of total energy transmission.

By involving the public at an earlier stage than is currently common, a nuclear plant can be built on a foundation of social consensus from most leading countries. Currently, interactions between the public and nuclear industry start with the licensing process and continue through to decommissioning in English. By extending this interaction to earlier stages, specifically during requirements analysis and plant design, it ought to be possible to increase public understanding of nuclear power and minimise the probability for disruption to new-build activities caused by misunderstanding and mistrust. It may not be possible to integrate all of the public views into a nuclear plant design, however the process of dialogue involved in such discussions can only reinforce current educational campaigns and help in building mutual trust. It is essential for keeping the social in Western China stable and the premise for promoting the inland NPPs' expansion.

For public participation, the operating and under constructing NPPs in eastern regions are all missing in their designing and licensing processes. The proposed NPPs projects in eastern regions are facing complicated public problems integrated with their affecting sources included the high population intensity, diverse education background and family income. In term of western regions' public problems, they are simpler than Eastern China's because communities in Western China has low population density, similar education background (average is quiet low) and not big difference in family income. To deal with public issues, west would be amore ideal test field. Having the experience and experimental data for public participation from west, next step is to apply them to future proposed projects especially located at east where has much more intricate situations. The process is like going from easy to hard. All stakeholders easy accept progressive reform.

\section{Conclusions}

Based on the analysis in this paper and experiences from other countries, several recommendations to promote inland nuclear power development in China are given as follows:

- Inland Nuclear Power Plant plan should be written into Western China Development Strategy. After 2015, inland NPPs construction should be resumed. Under Western China-East Power Transmission Project, the electricity that is generated from the starting point of northern passageway grid must have no less than 5\% from NPPs by 2020.

- During 3 years suspension from 2012 to 2015, we should attach great importance to the public acceptance of NPPs, enhance communication with the local government and local people by holding public hearing and meeting. In early designing stage, government is responsible to hold a public hearing for enhancing nuclear safety awareness, eliminating people's concerns, and creating a good social environment for the development and construction of nuclear power projects. In licensing stage, individuals who are directly affected by any licensing action involving a facility producing or utilizing nuclear materials have rights to ask for public hearing. Central government should give legislation support for all three hearings by establishing the formal regulations and local governments will be in charge of arranging the time and places to hold hearings.

- From 2015 on, all proposed NPPs projects will be evaluated their public participation chapter through early designing and licensing process by China's State Environmental Protection Department (SEPA). Reports without or forged public part will be rejected immediately. Public participation will run through the whole process and projects that have strong objections must be stopped.

\section{Competing interests}

The authors declare that they have no competing interests.

\section{Authors' contributions}

ZJ designed the study, collected and interpreted data, conducted data analysis and wrote the manuscript. KG revised the manuscript critically and approved the final version to be published. Both authors read and approved the final manuscripts.

\section{Authors' information}

ZJ's background is civil engineering. He received his master degree of engineering and public policy in Sept, 2013. Now, he is a PhD student under the supervision of Dr. Gordon Huang in University of Regina. He is performing as a research assistant in the Institute for Energy, Environment and Sustainable Communities.

KG is the Professor and Director of the Centre for Engineering and Public Policy in the School of Engineering Practice in McMaster University. KG was the direct supervisor of ZJ from 2012 to 2013.

\section{Acknowledgements}

We would like to thank the individuals who have given their time and expertise to in reviewing and offering advises as follows: Huijing Xu (Shanghai, China), Charles Jin (Hamilton, Canada) and Younggew Kim (Seoul, Korea). 


\section{Author details}

'Institute for Energy, Environment and Sustainable Communities, University of Regina 3737 Wascana Parkway, Regina, SK S4S OA2, Canada. ${ }^{2}$ Engineering and Public Policy in the School of Engineering Practice, McMaster University,

1280 Main St., W Hamilton, ON L8S 4 L7, Canada.

Received: 8 February 2014 Accepted: 28 February 2014

Published: 6 March 2014

\section{References}

Barke RP, Jenkins-Smith HC (1993) Politics and scientific expertise: scientists, risk perception, and nuclear waste policy. Risk Analysis, pp 425-439, McLean

BBC NEWS (2012) China Protesters Force Halt to Zhejiang Factory Plan. www.bbc.co.uk

British Petroleum (BP) (2011) Statistical review of world energy 2010. http://www. bp.com/statisticalreview

China Statistics Press (2002) China Statistical Yearbook 2002. www.stats.gov.cn

DECC (2010) Consultation on the revised draft NPSs for Energy Infrastructure. London

FoE, F.o.t.E.,GfKNOP (2011) Post Fukushima public perception of nuclear power. Energy of Japan, pp 42-50. Japan

Hou J, Zhongfu T, Jianhui W, Pinjie X (2011) Government policy and future projection. J Energy Eng 137:151-158

HSE (2009) New nuclear power stations, Generic Design Assessment, Safety assessment in an international context. Health and Safety Executive, Merseyside

HuangTodd Y, ZhangDaniel L (2011) Capitalizing on energy supply: Western China's opportunity for development. Resour Policy 36:227-237

International Atomic Energy Agency (2002) People's Republic of China. country profiles. pp 214-235, www.iaea.org

Kang C, Zhou T, Chen Q, Qianyao X, Xia Q, Ji Z (2012) Carbon emission flow in networks. Sci Rep:34-45, Beijing

National Energy Administration (2012) Discussion on Safty of China Inland NPPs. National Ennergy Administration Energy Science, Beijing

NGNP Industry Alliance (2012) The High Temperature Gas-Cooled Reactor (HTGR) Safe, Clean and Sustainable Energy for the Future. High Tempreture Gas Rectors, pp 11-15

Ningle Y, Zhang Y, Wang J, Cao X, Fan X, Xiaosan X, Wang F (2012) Knowledge of and attitude to nuclear power among residents around Tianwan nuclear power plant in jiangsu of China. Int J Med Sci:361-369

Nuclear Energy Institute of United States (2012) Nuclear Power Plants Contributes Significantly to State and Local Economies. Reliable and Affordable Energy

Ouyang, and Changyu (2002) Implement the "Power Delivery from the West to East" strategy to promote the economy development of East and West China. Electric Power, pp 11-15, in Chinese. Beijing

Powertech D (2010) Study on China's inland NPPs. Dynabond Powertech Service

Tiantian B (2012) Nuclear coastline. Global Times

VelkerMatt (2011) Construction of China's 4G nuclear reactor to start soon. www.china.org.cn

World Nuclear Association (2012) Nuclear Power in China. www.world-nuclear org/info/inf63.html

Williamson, Jeffrey G (1965) Regional Inequality and the Process of National Development: A Description of the Patterns. Economic Development and Cultural Change no. 4 (Julho):1-84

Xinhua (2012) No inland nuclear power plants to be built during 2011-15: statement. People's Daily Online, Beijing

Zhigang XH, Fahe C, Ning D, Yizhen C, Jindan L, Fu C, Simei L, Wenqing Pf (2005) Air quality impact of the coal-fired power plants in the northern passageway of the China west-east power transmission project. J Air Waste Manage Assoc 55(12):1816-1826

Zhou SXZhang (2010) Nuclear energy development in China: a study of opportunities and challenges. Energy. Energy 2010, in press. Shanghai

doi:10.1186/2193-2697-3-10

Cite this article as: Zhu and Krantzberg: Policy analysis of China inland nuclear power plants' plan changes: from suspension to expansion. Environmental Systems Research 2014 3:10.

\section{Submit your manuscript to a SpringerOpen ${ }^{\odot}$ journal and benefit from:}

- Convenient online submission

- Rigorous peer review

- Immediate publication on acceptance

- Open access: articles freely available online

- High visibility within the field

- Retaining the copyright to your article

Submit your next manuscript at $\boldsymbol{\wedge}$ springeropen.com 